\title{
AN EMPIRICAL ANALYSIS OF THE ANNUITY RATE IN CHILE
}

\author{
Roberto Rocha, Marco Morales, and Craig Thorburn ${ }^{1}$
}

\begin{abstract}
Empirical analyses of annuities markets have been limited to a few developed countries and restricted by data limitations. Chile provides excellent conditions for research on annuities due to the depth of its market and the availability of data. The paper utilizes a panel of life insurance company data to examine econometrically the main determinants of the annuity rate, defined as the internal rate of return on annuities. The results indicate that the annuity rate is determined by the risk-free interest rate, the share of privately-issued higher yield securities in the portfolio of providers, as a proxy for the spread over the risk-free rate, the leverage of providers, the level of broker's commissions, the market share of individual providers, the level of the premium, and the degree of market competition. The results also show that efforts to improve market transparency produced structural shifts in the parameters of the annuity rate equation. The results are consistent with separate research on money's worth ratios, and indicate the need to develop appropriate financial instruments, allowing providers to hedge their risks while extracting higher returns, and also to ensure competition and transparency in annuities markets, in order to ensure good outcomes for annuitants.
\end{abstract}

World Bank Policy Research Working Paper 3929, June 2006

The Policy Research Working Paper Series disseminates the findings of work in progress to encourage the exchange of ideas about development issues. An objective of the series is to get the findings out quickly, even if the presentations are less than fully polished. The papers carry the names of the authors and should be cited accordingly. The findings, interpretations, and conclusions expressed in this paper are entirely those of the authors. They do not necessarily represent the view of the World Bank, its Executive Directors, or the countries they represent. Policy Research Working Papers are available online at http://econ.worldbank.org.

\footnotetext{
${ }^{1}$ World Bank, Diego Portales University and World Bank, respectively. This paper was derived from a comprehensive report of the Chilean market for retirement products, coordinated by Roberto Rocha and Craig Thorburn, and part of a broader World Bank project on the payout phase of private pension systems involving several country studies. The authors are grateful to Sara Zervos and Ying Lin for valuable inputs provided in the early stages of the analysis. The authors are also grateful to Eduardo Walker, Dimitri Vittas, Augusto de la Torre, Augusto Iglesias, Guillermo Martinez, Solange Berstein, Guillermo Larrain, Alejandro Ferreiro, Ernesto Rios, Osvaldo Macias, Richard Hinz, and several industry participants for helpful comments on earlier versions of the paper.
} 


\section{Introduction}

The increased involvement of the private sector in pension provision has led to a substantial volume of research on the structure, performance, and regulation of private pension funds, both in developed and emerging countries. However, most of the analytical effort has been focused on the accumulation phase of private pension provision. There are fewer empirical analyses of the payout phase, which involves the transformation of the final balance into flows of retirement income through instruments such as annuities and phased withdrawals (PWs). Moreover, most empirical studies of the payout phase involve the computation of money's worth ratios (the ratio of the expected present value of annuity payouts to the annuity premium) or a simple comparison of the annuity rate (the internal rate of return on annuities) with market interest rates.

While these studies provide a measure of the performance of annuity markets, they do not provide an analysis of the determinants of such performance, particularly the set of determinants related to the structure and regulation of the insurance industry providing annuities. This is due in large part to the absence of sufficient data on annuity payouts, premiums, returns, commissions, the structure of the industry, and the individual characteristics of providers. The lack of critical statistical information is due in turn to several factors, including the immaturity of annuity markets in most countries and weak disclosure rules.

The absence of analysis on the structure and performance of the market for retirement products is cause for concern, as many countries have implemented pension reforms that have included the introduction of mandatory private pillars, and will need to face the payout phase in the near future. Policy-makers in these countries would benefit from more empirical analyses that provide insights and inputs to the design of sound regulation and institutional arrangements. This is particularly the case for annuities, products that involve very long contracts and complex risks.

Chile provides one of the most relevant experiences for countries that have reformed their pension systems and that face the challenge of developing markets for annuities and PWs. This is due to its well-known pension reform of 1981, which involved a move from a public pay-as-you-go (PAYG) system to a fully-funded (FF) system operated by the private sector. At the start of its pension reform in the early 1980s, Chile was a middleincome country without a pension industry, an incipient insurance sector, little regulatory and supervisory capacity, and undeveloped capital markets. Twenty-five years later Chile had reasonably developed markets for retirement products, evidenced by around 320,000 annuity policies and 200,000 PWs, and about 17 life insurance companies providing annuities and managing assets of almost 20 percent of GDP.

The Chilean case enables a more in-depth examination of the performance of annuities markets, not only because of the size of its market but also because of disclosure rules that open access to information on annuity rates, number of policies, premiums, commissions, and the financial statements of individual providers.

The purpose of the paper is to examine the main determinants of annuity rates in Chile, based on data reported by life insurance companies, and identify the regulatory factors that may influence the performance of annuity markets. The paper is structured as follows. The second section reviews briefly the evolution of the Chilean annuities market and the 
annuity rate in the 1990s and early 2000s. The third section presents an heuristic model of the supply and demand for annuities and discusses the main determinants of the annuity rate. The fourth section provides an analysis of the data used in the regressions. The fifth section presents a number of preliminary tests designed to identify the most appropriate estimation model. This includes tests for non-stationarity, model specification, and autocorrelation. The sixth section presents and discusses the estimation results. The last section summarizes the main findings and conclusions.

\section{A Brief Review of the Evolution of the Chilean Market ${ }^{2}$}

Chile's market for retirement products has its origins in the well-known pension reform implemented in 1981, involving the replacement of the PAYG system by a private and FF system that operates on a defined contribution (DC) basis. Under the new system, workers contribute 10 percent of their wages to an individual account, up to a ceiling of 60 unidades de fomento (UFs), the equivalent of about three times the average wage. The UF is a unit of account indexed to prices which is widely used in the valuation of contracts and tax parameters.

Workers can choose freely among different pension funds managed by pension fund administrators (Administradoras de Fondos de Pensiones - AFPs). In addition to the 10 percent contribution, workers also pay about 2.2 percent of their wages as commissions, part of which is used to pay for disability and survivorship insurance. At the time of retirement, workers use their accumulated balances to purchase an annuity from an insurance company or a PW from an AFP. Disabled workers are entitled to a disability pension and the dependents of deceased workers are entitled to a survivor's pension. Both disabled and survivorship pensioners can also choose between annuities and PWs.

As participation in the pension system is mandatory, the State provides some guarantees, including a minimum pension guarantee and a guarantee against the bankruptcy of annuity providers. The latter guarantee is partial - 100 percent until the level of the minimum pension and 75 percent of the amount above this level up to a maximum of 45 UFs per month, about twice the average wage.

Workers can retire from the pension system at the normal retirement age of 65/60 for men and women, respectively. A worker can retire early if he or she has accumulated a sufficient balance in his or her account. This was defined as the balance needed to generate a pension equal at least to 50 percent of his or her average real wage in the past 10 years, and at least 110 percent of the minimum pension. A new Pension Law adopted in 2004 raised these parameters to 70 and 150 percent, respectively.

Retiring workers can take a partial lump-sum subject to strict conditions, and can also choose among 3 retirement products: an annuity, a PW, and a temporary withdrawal (TW) combined with a deferred annuity. Relatively few workers draw partial lump-sums and the amounts are generally small. Annuities are provided by life insurance companies and are freely priced. Workers can choose among licensed companies upon retirement. Until recently, all annuities were fixed and indexed to prices. With respect to the PW option, the individual balance remains in the AFP and is drawn according to a formula that includes life expectancy. Upon death of the main beneficiary, the spouse continues

\footnotetext{
${ }^{2}$ A more detailed description of the annuities market can be found in Rocha and Thorburn (2006) and James, Iglesias and Martinez (2005).
} 
receiving the PW payments, and upon his/her death, the residual balance goes to the heirs as a bequest. TWs involve a fixed drawdown for a number of years (most commonly 1 year) followed by a deferred annuity, and can be considered as annuities for all practical purposes. PW holders may buy an annuity with the remaining balance provided that the annuity is larger than the minimum pension.

The number of pensioners under the new system has increased significantly, reaching 520,000 in 2004. As shown in Table 1, the increase in the number of pensioners has led to a strong demand for both annuities and PWs, and a fast growth of the Chilean insurance sector in the past decade. The rapid expansion of the insurance sector is reflected in the increase in total premiums from 2 percent of GDP in the mid-1980s to more than 4 percent of GDP in 2004, half of which comprising sales of immediate life annuities. Total assets also grew rapidly from 5 to 20 percent of GDP in the same period.

The number of retirees choosing annuities has increased considerably in the past 20 years. As shown in Table 1, the share of pensioners that has chosen annuities has increased to more than 60 percent, including the small number of TW holders. These numbers imply one of the highest rates of annuitization in the world. There is a strong association between annuitization and early retirement in Chile - 60 percent of all annuitants are early retirees and only 15 percent are normal age retirees. The remainder includes disabled retirees and survivors.

The high rate of annuitization in Chile and its relation to early retirement is the result of several factors. First, restrictions on lump-sums increase the demand for all retirement products, including annuities. Second, the absence of a PAYG benefit and the low level of the minimum pension imply that middle and higher income retirees who take PWs are substantially exposed to investment and longevity risks. Therefore, they may find attractive the protection provided by annuities. Moreover, these retirees tend to be early retirees precisely because only higher income retirees can meet the conditions for early retirement. Third, the marketing of retirement products is one-sided. AFPs focus on the accumulation phase of the pension business and do not market PWs actively. By contrast, life insurance companies depend on the annuity business and have marketed their products aggressively. Annuity brokers obtain their income from commissions on annuity premiums, frequently inducing workers to retire early and annuitize.

Table 1: Breakdown of Stock of Pensions, by Type of Instrument, 1990-2004

\begin{tabular}{c|c|cccccc}
\hline Year & Total & \multicolumn{2}{|c}{ PWs } & \multicolumn{2}{c}{ TWs } & \multicolumn{2}{c}{$\begin{array}{c}\text { Annuities } \\
\% \text { of } \\
\end{array}$} \\
& & Number & \% of Total & Number & \% of Total & Number & Total \\
\hline 1990 & 57,119 & 36,696 & $64.2 \%$ & 148 & $0.3 \%$ & 20,275 & $35.5 \%$ \\
1995 & 190,400 & 98,699 & $51.8 \%$ & 6,803 & $3.6 \%$ & 84,898 & $44.6 \%$ \\
2000 & 343,965 & 147,532 & $42.9 \%$ & 6,632 & $1.9 \%$ & 189,801 & $55.2 \%$ \\
2004 & 520,793 & 196,242 & $37.7 \%$ & 6,193 & $1.2 \%$ & 318,358 & $61.1 \%$ \\
\hline
\end{tabular}

Source: SAFP

The structure of the pension and life insurance sectors evolved very differently in the past 20 years. As shown in Figure 1, the pension sector has become very concentrated, with the number of AFPs declining from 20 to only 6. This reduction in the number of participants is reflected in the sharp increase in concentration ratios. By contrast, the fast increase in the number of annuity contracts in the 1990s attracted new entrants, increasing the total number of life insurance companies to 34 by the late 1990s, 23 of which provided 
annuities. The increase in the number of annuity providers in the 1990s led to a continuous decrease in concentration ratios. In recent years some life insurance companies have decided to exit the annuities segment of the life insurance market, discouraged by the intensive competition, the thin intermediation spreads and the relatively low returns on equity. These factors have resulted in an increase in concentration ratios, but the annuities sector in Chile remains more competitive than the AFP sector, whether measured by the number of participants or concentration ratios.

Figure 1

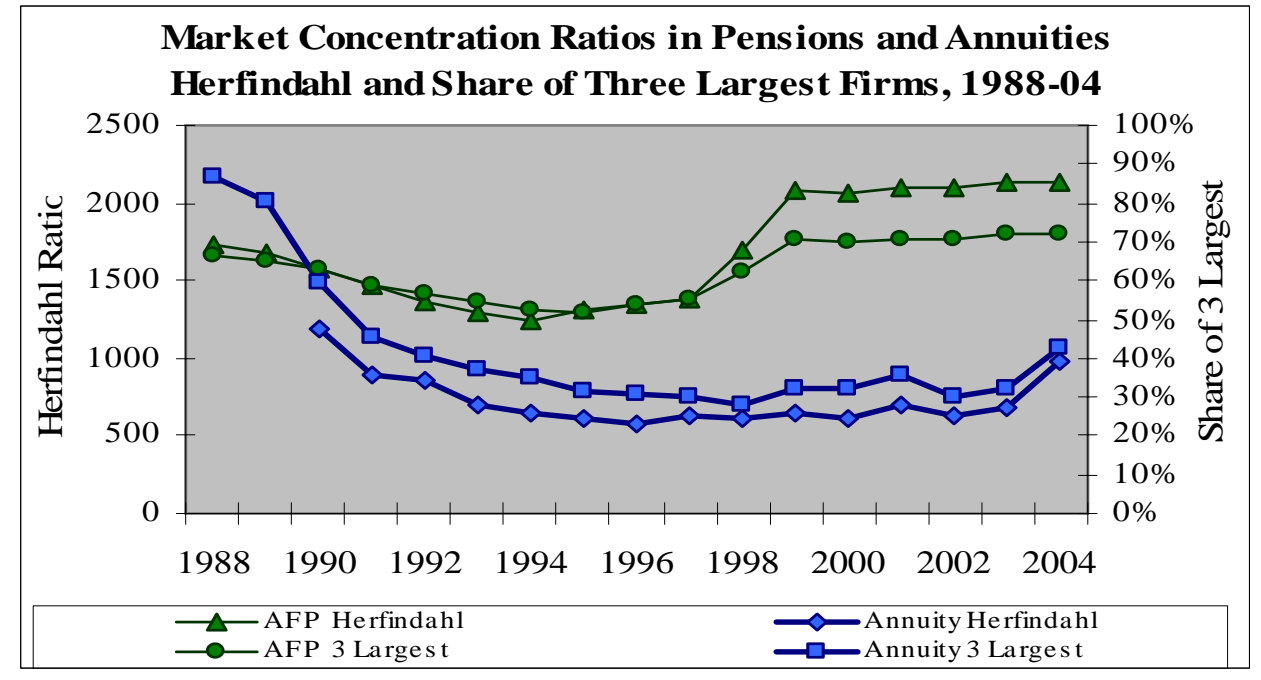

Source : SVS, SAFP

The performance of the annuities market can be measured by the relationship between the annuity rate (defined as the internal rate of return on the annuity) and the risk free rate. As shown in Figure 2, the average annuity rate reported by life insurance companies tracked the interest rate on 20 year Central Bank bonds reasonably well during the 1990s. ${ }^{3}$ In the early 2000s the difference between the two rates inverted, and the annuity rate has exceeded the risk-free rate since that point. This negative difference between the risk-free rate and the annuity rate is unusual. For example, Brown et al (2001) calculate the internal rates of return on US annuities and obtain rates ranging from 5.9 to 6.5 percent p.a., lower than the yields of 10 and 30-year Treasury bonds, which were 7.1 and 7.3 percent p.a. in the same period. James, Song and Vittas (2003) perform the same exercise for several countries and obtain similar results.

This inverted differential implies a good deal for annuitants but raises the question of whether providers have generated losses on their annuity business. Annuity providers can in principle pay higher annuity rates and still achieve positive spreads by investing in higher yield paper, and Table 2 indicates that the industry has shifted towards higher yield mortgage-related securities and corporate bonds since 1995. The move towards corporate bonds since 2000 is particularly noteworthy, with the share of this instrument increasing from 10 to almost 35 percent of the portfolio. These instruments are also indexed to prices and pay a higher yield than Government and Central Bank bonds, allowing providers to

\footnotetext{
${ }^{3}$ Until 2005 insurance companies had to calculate and disclose their annuity rates using the RV-85 mortality table. Since 2005 annuity rates have been calculated and reported with an updated mortality table, the RV04. The adoption of the RV-04 leads to higher annuity rates, with the difference amounting on average to about 50 basis points. For a more detailed discussion on the various mortality tables in Chile see Rocha and Thorburn (2006).
} 
match their long-term liabilities while extracting a higher return. Moreover, although the higher return on these instruments reflects in part a risk premium, it probably also reflects a liquidity premium that rewards investors for their much lower liquidity.

The search of annuity providers for higher risk-adjusted returns is also observed in other countries. For example, the Teacher's Insurance and Annuity Association-College Retirement Fund (TIAA-CREF), the largest annuity provider in the US, holds primarily privately-issued fixed income instruments to match its fixed annuities, as shown in Table 3. These instruments are much less liquid than government bonds, and include very illiquid corporate bonds bought through private placements. This portfolio strategy has arguably allowed TIAA-CREF to extract high risk-adjusted returns and share them with its annuitants. The question is whether the same type of strategy has allowed Chilean providers to pay a high annuity rate, cover their costs, and generate profits.

Figure 2

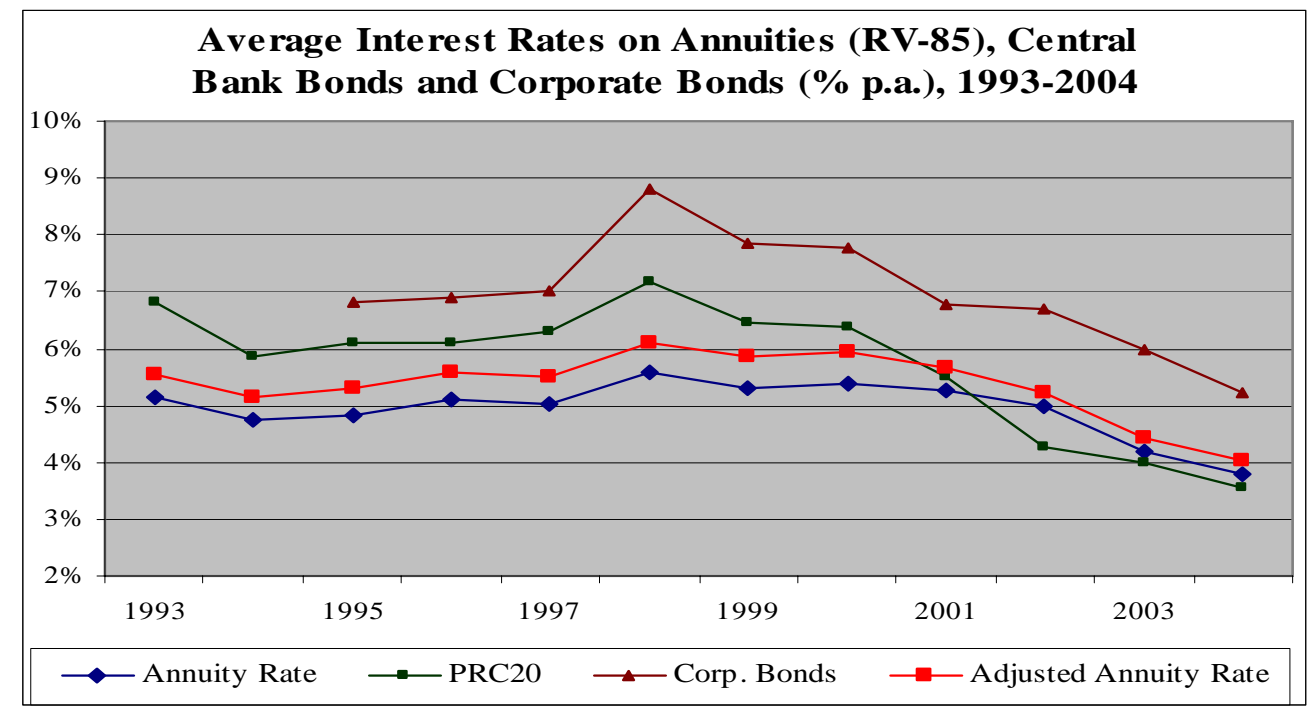

Sources: SVS, Central Bank of Chile.

Table 2: Portfolio of Life Insurance Companies (in \% of Total), 1991-2004 ${ }^{1}$

\begin{tabular}{lccccc}
\hline & $\mathbf{1 9 9 1}$ & $\mathbf{1 9 9 5}$ & $\mathbf{2 0 0 0}$ & $\mathbf{2 0 0 3}$ & $\mathbf{2 0 0 4}$ \\
\hline Government Sector & 38.3 & 40.3 & 28.7 & 17.6 & 17.1 \\
Financial Sector & 23.0 & 28.4 & 45.1 & 37.6 & 32.9 \\
$\quad$ Mortgage Bonds & 13.9 & 18.6 & 24.2 & 18.8 & 14.7 \\
$\quad$ Mortgage-Backed Securities & 3.0 & 6.0 & 10.1 & 10.1 & 9.2 \\
Company Sector & 29.0 & 22.1 & 15.3 & 33.4 & 37.8 \\
$\quad$ Shares & 8.9 & 10.2 & 3.4 & 2.9 & 3.4 \\
$\quad$ Bonds & 20.1 & 10.7 & 10.7 & 29.3 & 33.3 \\
Real Estate & 7.8 & 7.7 & 7.4 & 7.3 & 7.4 \\
Other Assets & 2.0 & 1.5 & 3.6 & 4.1 & 4.8 \\
Total & $\mathbf{1 0 0 . 0}$ & $\mathbf{1 0 0 . 0}$ & $\mathbf{1 0 0 . 0}$ & $\mathbf{1 0 0 . 0}$ & $\mathbf{1 0 0 . 0}$ \\
\hline
\end{tabular}

Source: SVS 
Table 3: TIAA Portfolio Backing Fixed Annuities, 2003

\begin{tabular}{l|c}
\hline Assets: & Percent of Total Portfolio \\
\hline Corporate Bonds (public issues) & 24 \\
Corporate Bonds (private placements) & 15 \\
Mortgage/Asset-Backed Securities & 33 \\
Commercial Mortgages & 16 \\
Real Estate & 4 \\
Equity & 4 \\
Other Assets & 6 \\
\hline Total & US\$150 billions \\
\hline Source: TIAA-CREF
\end{tabular}

Providers' costs include the commissions paid to annuity brokers and operating costs. As shown in Figure 3, commissions averaged 3 percent of the premium in the early 1990s, increased continuously to almost 6 percent at the end of the decade, and then decreased sharply to levels around 2 percent. The increase in the 1990s reflected the practice of charging higher commissions and providing an informal cash rebate to the retiring worker. This rebate proved a popular marketing device but was also illegal and prompted a reaction from policy-makers, which at the end of 2000 submitted a new Pensions Law to Congress. The draft Law proposed a cap on broker's commissions and a new electronic quotation system. Although the new Pensions Law was only passed in 2004, the threat of the Law and political pressure induced a change in behavior, as indicated by the sharp decline in commissions. $^{4}$

The commission cost adds about 30 basis points to the annuity rate, as shown by the adjusted annuity rate line in Figure 2, reducing the intermediation spread commensurately. In addition, providers also need to cover their operating costs, which have averaged 1.5 percent of assets. This implies thin net spreads, possibly negative for some providers. The question arises as to why profit-maximizing companies have issued annuities with such thin margins. It is possible that insurance companies have priced their annuities in the expectation of a future increase in interest rates, as well as lower operating costs due to increasing scale. There is also a possibility that some companies have adopted aggressive pricing strategies in order to drive competitors out of the market and gain market share. Industry participants and regulators acknowledge that intermediation margins have been thin and returns on equity low, and that is probably the reason why some life insurance companies have decided to exit the annuities market in recent years. ${ }^{5}$

\footnotetext{
${ }^{4}$ Walker (2005) examines the relationship between the annuity rate and the risk-free rate and concludes that the threat of the new Pension Law produced a change in behavior.

5 The average return on equity of insurance companies in the 1994-2004 period was only 4 percent, compared to 25 percent in the case of AFPs.
} 
Figure 3

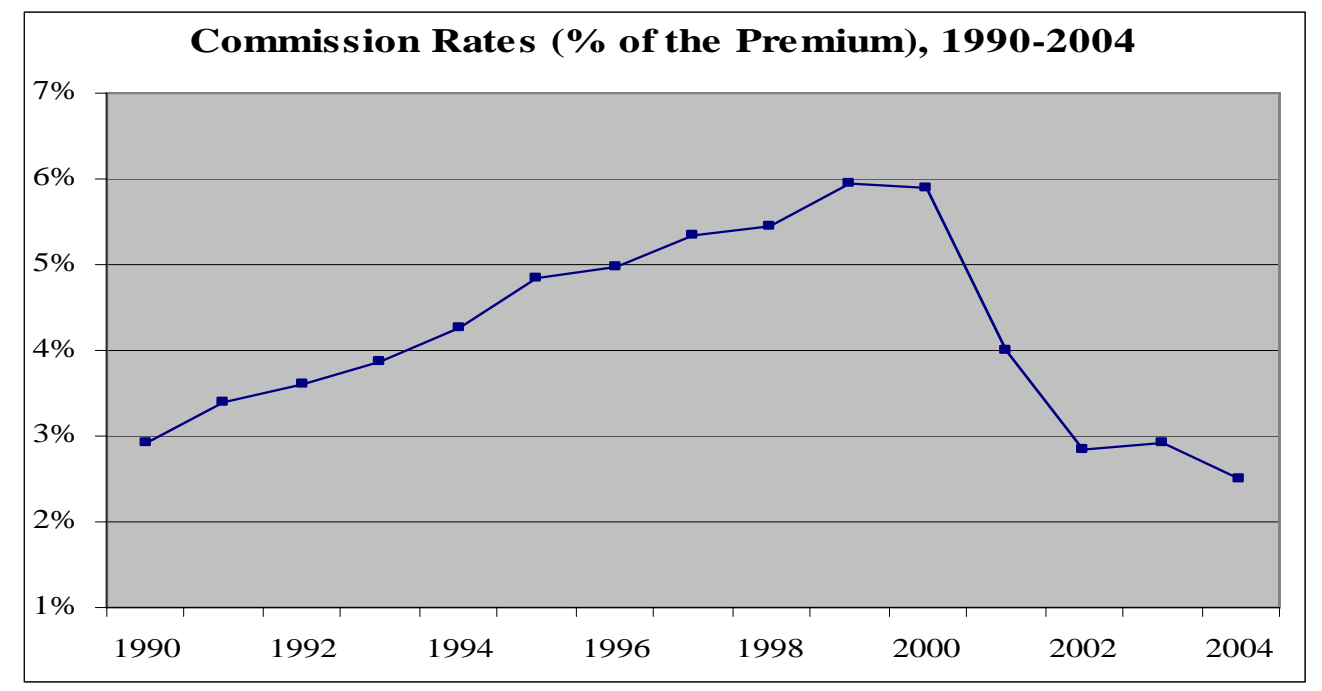

Source: SVS

\section{An Heuristic Model of the Annuity Rate}

The annuity rate is determined by the interaction of the flow demand and flow supply of annuities. The theoretical derivation of the flow demand and supply of annuities would require solving models of inter-temporal maximization for consumers and providers and is beyond the scope of this paper. Instead, this section follows an heuristic approach, examining the most important determinants of the annuity rate based on the factors that may affect the flow demand and supply of this product, both at the aggregate and the company levels.

The aggregate flow demand for annuities in any given period of time (e.g., a year) is determined by five major groups of factors: (i) the retirement rules, combined with the demographic structure of the working population; (ii) the history of contributions and the return performance of pension funds during the accumulation phase; (iii) the menu of retirement instruments, including lump-sums; (iv) the rate of return on annuities vis-à-vis alternative retirement instruments; (v) the risk profile and preferences of retiring workers. Each of these major groups of determinants is briefly examined below.

Retirement rules and the demographic structure of the working population together define the number of workers eligible for retirement in any given year, and the universe of potential annuitants in that year. For example, an increase in the regulated normal retirement age, or more stringent conditions for early retirement produce a decline in the number of retiring workers and a resulting contraction in the flow demand for all retirement products, including annuities.

The historic performance of pension funds (and the history of contributions) also affects the demand for annuities because it defines the size of the pension balance for any given cohort. For example, a prolonged and sustained period of higher returns results in larger pension balances, possibly leading several cohorts to anticipate retirement and increase the demand for all retirement products, including annuities. By contrast, negative returns on pension savings in the years preceding retirement may lead several cohorts to postpone retirement in order to achieve their target retirement income. A sharp drop in returns may also cause many retirees to fail to meet legal criteria for early retirement. 
The menu of retirement products is also a very important determinant of the aggregate demand for annuities. When lump-sums are allowed, the demand for annuities may be weak due to the adverse selection effect that has been extensively examined in the literature. ${ }^{6}$ The demand for annuities may be particularly weak if retiring workers are already covered by a PAYG benefit, i.e., if they are already substantially "annuitized". However, Chilean retirees do not receive a separate PAYG benefit at retirement, and lump-sums are severely restricted. These restrictions increase the potential demand for annuities in the Chilean case.

The aggregate demand for annuities also depends on the level of the annuity rate vis-à-vis the return on PWs, which is the only alternative retirement instrument in the Chilean case. The return on PWs depends fundamentally on market returns, as the balance remains invested in financial instruments. Finally, the demand for annuities depends on behavioral parameters such as the degree of risk aversion and the desire of retiring cohorts to leave bequests. However, these factors are important at the individual level but less important at the aggregate level, because it is argued that it is unlikely that they change significantly across different retiring cohorts.

The aggregate flow supply of annuities is derived from a long-run profit maximization process of all annuity providers, that takes into consideration the current and expected returns on financial assets, market annuity rates, operating costs, and proper consideration of all the complex risks involved in the annuity business, including longevity, reinvestment, and credit risk. Like banks, annuity providers also operate with intermediation spreads and attempt to maximize this spread adjusted for risk. The difference lies in the much longer time horizon involved in the annuity business and the greater complexity of the risks embedded in the annuity contract.

Figure 4 provides a starting point for analyzing the interaction of the flow aggregate demand and flow aggregate supply of annuities in Chile, and its impact on the annuity rate. The aggregate flow demand for annuities is shown as the upward sloping curve in Figure 4. A reduction in the annuity rate results, ceteris paribus, in a decline in the demand for annuities (measured by the number of new annuity policies in a given period of time) for two reasons. First, PWs (the alternative retirement product) become more attractive, leading new retirees to choose this instrument at the expense of annuities. Second, workers eligible for retirement may decide to postpone retirement, hoping for an increase in the annuity rates in subsequent years. They may also decide to retire but defer the annuity, also hoping for an increase in annuity rates.

As mentioned before, stricter conditions for retirement or poor pension fund performance in the pre-retirement period would both cause a reduction in the flow demand for annuities - in Figure 4 the demand curve would shift to the left. More interesting to the purpose of the exercise in this paper is the analysis of changes in interest rates and other market conditions. A general increase in interest rates vis-à-vis the annuity rate would imply an increase in PW returns and lead to a contraction in the aggregate demand for annuities. ${ }^{7}$ Other factors that could affect the aggregate demand for annuities include a move by all annuity providers towards riskier portfolio strategies or increased leverage.

\footnotetext{
${ }^{6}$ See, e.g., Brown et al (2001).

${ }^{7} \mathrm{An}$ increase in interest rates could also reduce the demand for new annuities by producing a capital loss in the accumulated pension balance.
} 
The perception of greater risk associated with annuities could lead potential annuitants to demand a risk premium, also shifting the demand curve to the left.

The aggregate flow supply of annuities is shown as the downward sloping curve in Figure 4. The aggregate supply is downward sloping because the annuity rate is the basic cost of issuing new annuity contracts. An increase in annuity rates relative to the interest rates on financial assets implies a reduction in intermediation spreads and profit margins for annuity providers, and a loss of enthusiasm in issuing new annuity policies. A general increase in interest rates for the same annuity rate implies an increase in spreads and profit margins and would lead to a supply expansion-in Figure 4 the aggregate supply would shift to the right. Changes in market structure resulting in greater industry concentration and increased monopoly power would lead to a contraction in the aggregate supply-in Figure 4 the aggregate supply would shift to the left.

Figure 4: Supply and Demand for Annuities

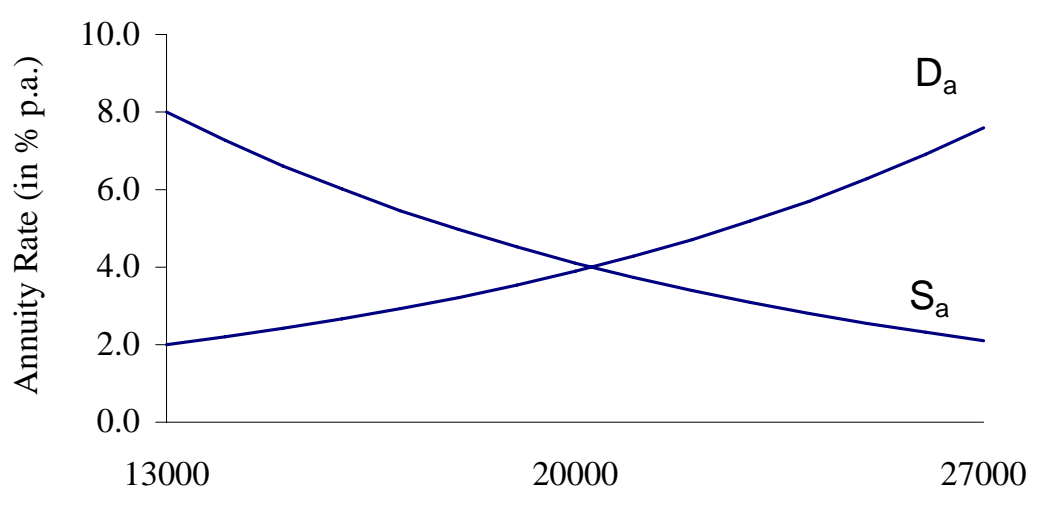

Number of New Annuity Policies

Market equilibrium is illustrated in Figure 4 with an annuity rate of 4 percent and 20,000 new annuities issued within one year (these are roughly the figures for 2004). A general increase in interest rates would lead to a contraction in demand and an expansion in supply, with ambiguous effects on the flows of new annuities, but producing an unambiguous increase in annuity rates. This simple framework also allows the analysis of the impact of other variables on the annuity rate. For example, a general portfolio shift from government bonds to higher yield corporate bonds could result in an expanded supply of annuities and a higher annuity rate. Providers would expand supply and increase the annuity rate if they could extract an increase in the risk-adjusted return. This would be possible if the yield on corporate bonds contained a liquidity premium. If annuitants perceive an increase in risk and demand a risk premium, the aggregate demand would contract, reinforcing the increase in the annuity rate. Again, the effect on the new flows of annuities is ambiguous, but the impact on the annuity rate is unambiguously positive.

The equilibrium depicted in Figure 4, where the market is cleared by one annuity rate, admittedly simplifies the structure and organization of annuity markets. First, the market comprises several types of annuities and rates. Second, adverse selection may restrict severely the overall size of the market, and for some risk segments there may not be a market clearing annuity rate. In a scenario of high and volatile interest rates the market 
may also collapse, as providers may require very high spreads or even refuse to take the underwriting risk. However, if the potential annuitant population is large, because the private pension system is mandatory, adverse selection is reduced by the existence of a mandatory private system and restrictions on lump-sums, and macroeconomic conditions are stable - the conditions observed in Chile during the 1990s and early 2000s-this simple framework can be applied as the basis for an empirical analysis of the annuity rate.

In the case of Chile, therefore, it seems possible to specify an annuity rate equation as a reduced form equation of an underlying structural model of the demand for and the supply of annuities. Introducing company-level characteristics, such a reduced form equation can be written as:

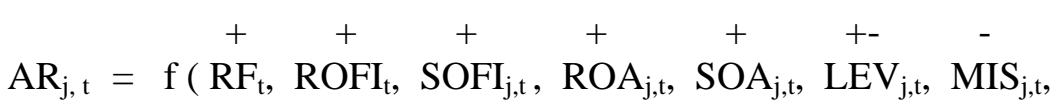

$$
\begin{aligned}
& +-\quad+-\quad-\quad \text { - } \\
& \text { MSHARE }_{\mathrm{j}, \mathrm{t}}, \mathrm{AP}_{\mathrm{j}, \mathrm{t}} \mathrm{CR}_{\mathrm{j}, \mathrm{t}}, \mathrm{HER}_{\mathrm{t}} \text { ) }
\end{aligned}
$$

Where AR is the average annuity rate of the annuities offered by company $\mathrm{j}$ at time $\mathrm{t}$ (the subscripts $\mathrm{j}$ and $\mathrm{t}$ will not be repeated hereafter); RF is the risk-free rate; ROFI is the rate of return on other fixed income instruments; SOFI is the share of other fixed income assets in the fixed income portfolio of providers; ROA is the rate of return on other assets; SOA is the share of other assets in the portfolio of providers; LEV is the financial leverage; MIS is the duration mismatch; MSHARE is the market share measured by the stock of technical reserves; AP is the average annuity premium; CR is the commission rate; and HER is the degree of industry concentration measured by the Herfindahl index. The variables RF, ROFI, ROA, and HER are common to all the companies, whereas the others are company-specific. The equation also shows the expected sign of the coefficient.

An increase in RF, the risk-free rate, leads to an increase in the annuity rate, for the reasons already elaborated above. The risk-free rate, measured by the interest rate on Government or Central Bank bonds, is one of the most important determinants of the annuity rate, as it is the key reference rate for both annuitants and providers-it captures the basic opportunity cost for potential annuitants and the basic return on assets for annuity providers.

An increase in the rate of return on other fixed income instruments, ROFI, (measured by the interest rates on corporate bonds), or on other assets, ROA (measured by the return on equity and foreign exchange assets), for the same levels of RF, could also lead to an increase in the annuity rate, although such an increase would arguably have to happen on a risk-adjusted basis - if agents are taking risk properly into account, an increase in the rates of return on financial assets due entirely to risk could have little impact on the demand or supply of annuities. The major problem in utilizing these variables is, however, their very high correlation with RF.

A more promising route to test the impact of portfolio variables on the annuity rate is to use the share of the main classes of privately-issued assets in the overall portfolio. The share of other fixed income assets, SOFI, and other assets, SOA, may capture the portfolio strategies of annuity providers and their attempts to extract additional returns and remain competitive in the annuities market. An increase in these shares would imply an increase 
in expected portfolio returns for the same levels of ROFI, ROA, and RF. If this increase in the expected portfolio return reflects factors other than risk, competitive pressures could lead providers to share them with annuitants. This would be possible if the spread of corporate bonds over government bonds reflects not only default risk but also other factors such as a liquidity premium. ${ }^{8}$ If potential annuitants perceive an increase in risk associated with a higher share of these assets they would demand a risk premium and the impact on the annuity rate would be stronger. In any case, the impact of SOFI and SOA on the annuity rate would seem unambiguously positive. An increase in LEV, or the financial leverage of providers, should also have a positive impact on the annuity rate, given the higher levels of risk involved.

Walker (2005) examines the impact of different portfolios and leverage ratios on the annuity rate under a stylized Modigliani-Miller framework, and concludes that an increase in the share of risky assets or an increase in leverage could have a positive impact on the annuity rate. The impact of an increase in financial leverage on the annuity rate would be modest if providers held primarily risk-free assets, but could be significant if providers held a significant share of riskier assets. ${ }^{9}$

The variable MIS measures the mismatch in the duration of provider assets and liabilities. The average duration mismatch in Chile has ranged from 3 to 4 years, with some variations across companies and over time. Such a duration mismatch penalizes providers in at least two ways. First, it exposes providers to changes in interest rates, or more specifically to reinvestment risk. Second, it also penalizes providers through reserve regulations, which impose larger reserves the greater the duration mismatch. Therefore, an increase in the mismatch, either across providers or over time, should lead to a contraction in supply and lower annuity rates.

The variable MSHARE represents the market share of each company, measured by the stock of technical reserves, and can have multiple and conflicting effects on the annuity rate. A large market share captures absolute size and should reflect the capacity of companies to achieve lower costs through economies of scale. Companies with lower operating costs should be able to compete more effectively and offer higher annuity rates. At the same time, a large market share may also be associated with reputation and brand name in the market, allowing companies to pay lower annuity rates, relative to less known newcomers attempting to gain market share. A large market share may also be a proxy for the size of the sales force and the number of branches and distribution channels. Companies with better distribution channels may also be able to attract customers paying lower annuity rates and lower commission rates (the role of brokers in the annuity market is further elaborated below). ${ }^{10}$

The impact of the average premium, AP, on the annuity rate cannot be determined $a$ priori. On the one hand, the size of the annuity premium is associated with levels of worker wealth and education, which are positively correlated with expected longevity.

\footnotetext{
${ }^{8}$ Most empirical studies on corporate bond spreads conclude that default risk does not explain all the observed spread, and that taxes, liquidity, and market risk factors explain the difference. See Duffee (1999), Deliandes and Geske (2001), and Elton, Gruber, Agrawal, and Mann (2001).

${ }^{9}$ Walker (2005) makes these predictions but does not test them empirically. Such an empirical analysis is provided below.

${ }^{10}$ Market share is measured by the stock of reserves, rather than the flows of new annuity policies or flows of annuity premiums. These flows are essentially the endogenous quantity variable in the heuristic model outline above, and cannot be included in a reduced form equation.
} 
From this aspect, a higher annuity premium should lead to lower annuity rates (when annuity rates are measured with the same mortality table, as is the case). However, life insurance companies value customers with larger annuity premiums, just like commercial banks value customers with larger deposits, because they involve lower unit costs and higher unit profits for the providers. Therefore, annuity providers may be willing to pay higher annuity rates for larger premiums, just like banks pay higher interest rates for larger deposits. In fact, some annuity providers seem to specialize in the upscale annuity market, just like some banks specialize in the corporate sector or in the upscale consumer market, avoiding the higher costs associated with retail banking, for the same levels of scale, and being able to pay higher rates for higher income consumers. ${ }^{11}$

The variable CR measures the commission rate, defined as the ratio of broker commissions to the premium. In Chile as in other countries, annuities can be sold either by sales staff, which are employees of an insurance company, or by independent brokers. As shown in section 2, commission rates increased continuously in the 1990s and then declined rapidly in the early 2000s as a result of political and supervisory pressures. An increase in the commission rate has an unambiguously negative impact on the annuity rate, due to several factors operating both on the side of demand and the side of supply of annuities-under the heuristic model outlined above a higher commission rate leads simultaneously to an expansion in the demand and a contraction in the supply of annuities. These effects are further elaborated below.

The level of commissions reflects the broker's efforts to search for new customers and induce eligible workers to retire. In general, it is likely that the intensity of broker activity replaces the annuity rate as marketing device, leading eligible workers to buy an annuity without a complete market search. In some cases the broker may provide services which are valued by the consumer, such as the verification of the conditions for retirement and all the required paperwork. The eligible worker may be more willing to sacrifice market search when these services are provided. There is an even more direct and powerful substitution effect between the commission rate and the annuity rate when the commission is partly shared with retiring workers. The illegal practice of sharing the commission was a loophole in the system that allowed workers de facto access to a modest lump-sum. Several of these workers were probably willing to accept a lower annuity rate in exchange for such an informal lump-sum.

An increase in commission leads to a contraction in supply because it implies an increase in company's costs. The company needs to issue an annuity based on a smaller premium net of commissions. If interest rates, operating costs, and all other variables remain constant, the only way to preserve profit margins is to reduce annuity payments and the annuity rate. From another angle, the company will try to maintain constant the adjusted annuity rate, which is the annuity rate plus the capitalized value of the commission.

Finally, the variable HER captures the degree of industry concentration, as measured by the Herfindahl index. An increase in the Herfindahl index due to a reduction in the number of market participants should reflect the greater monopoly power of incumbents

\footnotetext{
${ }^{11}$ Most studies of economies of scale in banking and other areas of the financial sector involve the estimation of a cost function that includes a measure of scale such as assets or the number of accounts, complemented by a variable measuring the average balance. Average costs are shown to decline both with larger scale and larger average balances.
} 
and be accompanied by a contraction in aggregate supply and ultimately a lower annuity rate.

\section{The Data}

The sample is based on pooled quarterly data of active annuity providers over the 19932003 period. The sample starts in the first quarter of 1993 and ends in the third quarter of 2003, yielding a total of 43 quarters. The number of active providers ranged from 17 to 24 during the period under examination. This yields a total of 693 observations. The time unit is the quarter because of some limitations on monthly data. First, balance sheet data on the providers such as the portfolio composition, reserves, and leverage are only available quarterly. Second, some series such as annuity rates and commissions are available monthly, but suffer from discontinuities, due to the fact that many active providers do not sell annuities every month. All the flow variables were constructed by computing averages of the monthly figures within the quarter. The stock variables are end of quarter figures. The Insurance Supervisory Agency (Superintendencia de Valores y Seguros - SVS) was the source of most of the raw data used in the analysis. Market interest rates were obtained from the Central Bank of Chile.

$\mathrm{AR}_{\mathrm{j}, \mathrm{t}}$ is the average annuity rate of each company during the quarter, computed by the average of monthly rates, weighted by the premiums. Each company needs to calculate the annuity rate of every annuity issued (the tasa de venta), based on a regulated mortality table (which was the RV-85 during the sample period). ${ }^{12}$ The SVS databank provides a breakdown of annuity rates by type of policy, i.e., early retirement, normal age retirement, disability, and survivors of deceased members. The empirical analysis focuses on the annuity rates for early retirement policies AR(EARLY), and normal age retirement policies, AR(OLD).

The risk-free rate, $\mathrm{RF}$, was measured by the interest rate on 20 year indexed bonds issued by the Central Bank of Chile (PRC-20). The instrument was discontinued in 2002, but secondary market quotations are available after that date and were used to complete the series. Monthly data on interest rates on corporate and mortgage bonds are available from the SVS, but only since 1995, and reflecting instruments with varying maturities, possibly resulting in some consistency problems. Estimates of the returns of other risky assets such as equity can be obtained, but there are no direct data on the returns on foreign assets held by annuity providers.

The share of other fixed income assets, SOFI was measured by the combined share of corporate bonds, mortgage bonds, endorsable mortgages, and other fixed income assets in the total fixed income portfolio. The share of other assets, SOA, was measured by the combined shares of variable income and foreign assets in the total portfolio. Leverage, LEV, was measured by the ratio of technical reserves to equity. The duration mismatch, MIS, was measured by a coefficient reported by companies to the supervisor, under capital rules. ${ }^{13}$ Market share, MSHARE, was measured by dividing the technical reserves of each

\footnotetext{
${ }^{12}$ Companies are free to use their own mortality tables for pricing annuities, but they have to report annuity rates based on regulated mortality tables. During the period of analysis annuity rates were calculated and reported with the RV-85. The calculation of annuity rates with the updated RV-04 would produce primarily a level effect and would not change the results significantly.

${ }^{13}$ Capital rules for annuity providers penalize duration mismatches, as mentioned before. See Rocha and Thorburn (2006) for a detailed description of capital rules.
} 
company by total technical reserves in the system. Note that technical reserves account for a large share of the balance sheet and also constitute a good proxy for scale.

The average premium for each company, AP, is directly available from the SVS databank, broken down by class of annuity, including old age AP(OLD) and early retirement policies, AP(EARLY). The quarterly figure is simply the average of the monthly figures. The commission rate was computed by dividing the payments to brokers by the total premium. Finally, the Herfindahl index was constructed on the basis of company premia (or annuity sales). As in the case of average premium, the Herfindahl index was also constructed separately for early retirement policies, HER(EARLY), and normal old age policies, HER(OLD).

\section{Econometric Results}

The econometric analysis of the annuity rate involves the following preliminary steps. First, the series are tested for non-stationarity through a set of unit root tests, and a solution to deal with non-stationarity is elaborated. Second, several specification tests are conducted, involving pooled OLS versus Fixed Effects, pooled OLS versus Random Effects, and Fixed versus Random Effects. Third, after identifying the best estimating model, a test of autocorrelation is performed to select an appropriate robust variancecovariance matrix estimator and conduct inference about estimated coefficients.

\subsection{Unit Root Testing}

Table 4 presents a summary of the unit root tests performed for each series. All the tests considered have a unit root process as the null hypothesis, either a common one for all the companies or a specific process for each company. The figures in Table 4 correspond to asymptotic p-values for each test statistic. Therefore, a number lower than 0.05 means that the null hypothesis of a unit root is rejected at the 5 percent significance level.

The first test statistic (LLC) is due to Levin, Lin, and Chu (2002). In this case, the null hypothesis is a common unit root process for all the cross-section units. The statistic is based on a basic ADF (Augmented Dickey-Fuller) specification for each cross-section, but with the same AR(1) coefficient for all of them. The test is a modified t-statistic for the coefficient of interest ( 1 minus the autoregressive parameter) from a pooled regression involving standardized variables. For the specification of the ADF regressions, an information criterion is required (such as AIC or BIC) to select the optimum number of

lags and capture the autocorrelation in the series. In addition, to modify the standard tstatistic, a kernel-based spectral density estimator at frequency zero is computed (by using the corresponding bandwidth truncation selection method). Under the null of a common unit root process, the final test statistic is asymptotically distributed as $\mathrm{N}(0,1)$.

The second statistic (IPS) was proposed by Im, Pesaran, and Shin (2003). In this case, the null hypothesis is a specific unit root process for each individual cross-section unit. To compute the unit root test statistic, an ADF regression is specified for each cross-section, and then the average t-statistic for the individual coefficients is adjusted by using the expected mean and variance of the individual t-statistics. As in the previous test, an optimum lag order is required for the construction of the ADF regressions. The IPS test also has an asymptotic $\mathrm{N}(0,1)$ distribution. 
Finally, the Fisher (ADF) statistic proposed by Maddala and Wu (1999), and Choi (2001), is based on the idea of Fisher (1932) of combining p-values from individual unit root tests. Again, for a Fisher test based on ADF specifications for each cross-section unit, information criteria are required to choose the required lag order to have white noise residuals. The combined test statistic is asymptotically distributed as a Chi-square with $2 \mathrm{~N}$ degrees of freedom.

All the three test statistics are constructed using the Modified Akaike Information Criterion (MAIC), proposed by Ng and Perron (2001), which reduces the well known size distortions commonly present in unit root tests when the autocorrelation structure is characterized by high negative MA components. When required, the long-run variance is estimated through a Quadratic Spectral Kernel with automatic bandwidth selection method proposed by Andrews (1991). As deterministic components, both fixed effects and fixed effects plus a time trend are considered for each test statistic.

As shown in Table 4, the null hypothesis of a unit root is rejected for the two annuity rates, SOFI, LEV, AP(OLD), MIS, and MSHARE. The non-rejection of unit roots in the other variables seems to be related to the presence of a structural change in the intercept of their deterministic trend, which occurs at the end of the sample. As stated by Perron (1989), unit root tests are not consistent against the alternative hypothesis of trend stationary processes when the trend contains a shift in the slope. Moreover, although the tests are consistent when the shift is in the level of the trend (intercept), their power is remarkably lower. Therefore, breaks in the deterministic function of a trend stationary series are likely to produce the non-rejection of the null of a unit root.

Table 4: Panel Unit Root Tests (p-values)

\begin{tabular}{l|cccccc}
\hline \multirow{2}{*}{} & \multicolumn{2}{|c}{ LLC } & \multicolumn{2}{c}{ IPS } & \multicolumn{2}{c}{ FISHER(ADF) } \\
\cline { 2 - 7 } & Const. & +Trend & Const. & +Trend & Const. & +Trend \\
\hline AR(EARLY) & 0.9894 & 1.0000 & 0.5757 & 1.0000 & 0.0240 & 0.9997 \\
AR(OLD) & 0.0048 & 0.0004 & 0.2611 & 0.7633 & 0.0000 & 0.7318 \\
RF & 0.9994 & 0.9947 & 0.9998 & 0.9778 & 0.9996 & 0.9775 \\
SOFI & 0.9527 & 0.8834 & 0.9997 & 0.1185 & 0.9953 & 0.0008 \\
SOA & 0.9231 & 1.0000 & 0.9260 & 0.8663 & 0.9703 & 0.2582 \\
LEV & 0.0061 & 0.9875 & 0.0000 & 0.0412 & 0.0000 & 0.0064 \\
MIS & 0.7051 & 0.0000 & 0.0487 & 0.0000 & 0.0000 & 0.0000 \\
MSHARE & 0.0000 & 0.0001 & 0.0013 & 0.9666 & 0.0000 & 0.0000 \\
AP(EARLY) & 1.0000 & 1.0000 & 0.4185 & 0.8368 & 0.4600 & 0.5527 \\
AP(OLD) & 1.0000 & 1.0000 & 0.5273 & 0.0203 & 0.1218 & 0.0000 \\
CR & 0.9990 & 0.9999 & 0.9997 & 0.9997 & 0.9998 & 0.7720 \\
HER(EARLY) & 1.0000 & 1.0000 & 0.9988 & 1.0000 & 0.9983 & 0.9122 \\
HER(OLD) & 0.0018 & 0.9918 & 0.0000 & 0.0000 & 0.0000 & 0.0000 \\
\hline
\end{tabular}

If the series are considered as trend-stationary and some of them affected by a discrete change in the intercept of their deterministic trend, this deterministic non-stationarity can be addressed by including in the regressions a time trend plus an additive dummy variable. According to the Frisch-Waugh-Lovell theorem (Frisch and Waugh (1933), and Lovell (1963)), the numeric value of the coefficients of interest are the same, either if the regression includes detrended variables (the residual from the regression of the original 
variable on a constant, the additive dummy, and a time trend) or if the dummy and trend are included as additional explanatory variables in the regression. Finally, with the annuity rate (AR) considered as a stationary process, the inclusion of a potential nonstationary independent variable is not longer a big concern, since in this case there is no possibility of spurious correlation.

\subsection{Specification Testing}

There are three alternative models to consider in the estimation of the annuity rate. The first is a pooled OLS regression where no heterogeneity is allowed. The second is a fixed effects model where a specific constant term for each cross-section unit is considered. Finally, the third is a random effects specification which assumes that the heterogeneity comes in the form of an error component model (as part of the individual disturbance terms). The testing procedure is conducted as follows. First, the pooled OLS model is tested against the Fixed Effects specification. Second, the pooled OLS is compared to the Random Effects model. Finally, these two alternative specifications are compared to select the way to model the cross-section heterogeneity.

In the first case, the null hypothesis of pooled OLS is strongly rejected in favor of a Fixed Effects model, based on both an F-statistic and a Likelihood Ratio test. The values of the statistics are 5.8 and 128.1, respectively, while the corresponding critical 5 percent significance level for the $\mathrm{F}$ and Chi-squared distributions are 1.5 and 35.2, respectively. The null hypothesis of a pooled OLS model is also rejected in favor of a Random Effects specification, based on the results of the Breusch-Pagan (BP) Lagrange Multiplier test. The value of the BP statistic is 59.8, compared to the value of the Chi-squared distribution with 1 degree of freedom of 3.8. This conclusion is supported by the more powerful test proposed by Honda (1985), where the alternative hypothesis is one sided (considering that the variance components are non-negative) and also robust to non-normality. The value of the Honda statistic is 7.7, compared with a 1.6 value for the standard Normal distribution for a 5 percent significance level.

Given the rejection of the pooled OLS model against both the Fixed and Random Effects, it is possible to compare the two alternatives by a Hausman's type test. The main idea behind this statistic is that under the null hypothesis both the Fixed and Random Effects specifications are consistent (and the GLS estimator is efficient), given that individual effects are not correlated with the exogenous variables in the model. However, under the alternative hypothesis, the Random Effects model is inconsistent. This way, a large Wald statistic comparing the two estimated parameter vectors (weighted by the inverse of the difference of their variance-covariance matrices), should be taken as evidence in favor of the Fixed Effects specification.

The Hausman statistic is constructed following Ahn and Low (1996), by using an artificial regression of the GLS residuals $\left(\widetilde{e}_{i t}\right)$ on cross-sectional demeaned exogenous variables (that is $X_{i t}^{*}$, the same transformation applied to independent variables to compute the

Fixed Effects estimator) and their corresponding means $\left(\bar{X}_{i}^{*}\right)$. The test statistic is finally computed as NT (number of effective observations) by the R-squared from the artificial regression above, and distributed as Chi-squared with as many degrees of freedom as exogenous variables in the original model. Under these conditions, the Hausman statistic has a value of 66.9, while the asymptotic critical value at the 5 percent significance level is 
16.9. Hence, these tests favor the Fixed Effects specification to model the cross-section heterogeneity.

\subsection{Autocorrelation Testing}

Given the long time series dimension of the panel utilized, autocorrelation could be a more serious problem than heteroskedasticity. To test for AR(1) autocorrelation under Fixed Effects, it is possible to use an extension of the Breusch-Godfrey (BG) Lagrange Multiplier statistic. To compute the BG test, the first step is to run an auxiliary regression of the residuals from the Fixed Effects model on the independent variables and the first lagged residual. The R-squared from this regression is then multiplied by the number of observation in the sample. The BG statistic takes a value of 38.5, while the asymptotic Chi-squared distribution with 1 degree of freedom at the 5 percent significance level corresponds to 3.8. Therefore, the null hypothesis of no first order serial correlation under Fixed Effects is strongly rejected.

In order to ensure an appropriate inference about estimated coefficients, a heteroskedasticity-autocorrelation consistent covariance matrix for estimated parameters is required if the disturbance term is not a white noise process. Given that the Fixed Effects estimator is unbiased and consistent, but inefficient under non-spherical errors, an adjusted variance-covariance matrix for estimated parameters is enough to make consistent inference about the model. As suggested by Arellano (1987), an estimate of the asymptotic variance for the Fixed Effects estimator, which is valid under heteroskedasticity and serial correlation of arbitrary forms, is given by

$$
V\left(\hat{\beta}_{F E}\right)=\left(\sum_{i=1}^{N} X_{i}^{*} X_{i}^{*}\right)^{-1}\left(\sum_{i=1}^{N} X_{i}^{*} e_{i}^{*} e_{i}^{*} \cdot X_{i}^{*}\right)\left(\sum_{i=1}^{N} X_{i}^{*} X_{i}^{*}\right)^{-1}
$$

Even though this asymptotic variance is consistent for relative small $\mathrm{T}$ and large $\mathrm{N}$, for the unbalanced panel at hand, where some cross-section units have just a few effective observations (and on average there are 28 observations per unit), its use seems appropriate. The number of cross-section units considered for estimation is 24 .

\section{Estimation Results}

The analysis of the estimation results focuses on the regressions with the annuity rate of early retirement policies as the dependent variable, because early retirement annuities constitute the bulk of the annuities market, accounting for 60 percent of the whole stock of annuities and 70 percent of the flows of new annuities. Excluding disability and survivor annuities, their shares in the stock and the new flows of annuities are both around 80

percent. The regressions with the annuity rate of normal old age policies are shown at the end of the section.

Table 5 shows the estimates of equation (1) with the fixed effects model, excluding ROFI and ROA. The interest rate on other fixed income assets, ROFI, was excluded because it turned out to be non-significant, due to the strong colinearity with the risk-free rate-as shown in Annex Table 1, the correlation coefficients between the interest rates on PRC-20, corporate bonds and mortgage bonds were 0.86 and 0.92, respectively. The interest rate on other assets, ROA, was excluded because it could not be computed, due to the lack of data on the return on foreign assets. The quarterly return on equity can be computed but 
also turned to be non-significant. As mentioned before, these results are expected and do not affect the exercise, because the shares of other fixed income assets and other assets, capture the expected return of the portfolio of annuity providers.

As shown in Table 5, the regression explains about 80 percent of the variations of the annuity rate across companies and over time, the coefficients of all explanatory variables have the expected signs (or signs that can be reasonably explained in the cases where it could be either positive or negative) and are significant, with the exception of MIS. The coefficient of the risk-free rate is 0.37 , only slightly higher than the value obtained by Walker (2005) in a regression of the annuity rate against the lagged risk-free rate using monthly data. This coefficient looks low, as one would expect a tighter relationship between the annuity rate and the key interest rate, and possibly a coefficient close to one. The relationship between the annuity rate and the risk-free rate will be examined in more detail below.

The coefficients of SOFI and SOA are positive and significant, capturing the impact of portfolio strategies on the annuity rate. As shown in Table 2, during the sample period there were two major portfolio shifts, namely, a reduction in the share of equity from 10 percent in 1995 to about 3 percent in all the following years, and a sharp increase in the share of mortgage and corporate bonds, from 37 percent in 1995 to 66 percent in 2003. The share of Central Bank bonds decreased proportionately. The decline in the share of equity happened as insurance companies sold their equity holdings to foreign strategic investors in the mid-1990s at attractive prices. These prices reflected the large capital gains accumulated in previous years and possibly a control premium. It is clear that asset managers decided not to rebuild their equity portfolio after that event, in order to reduce the duration mismatch and possibly perceiving that the period of exceptional equity returns was over. This perception may have resulted in an overall downward adjustment of average expected portfolio returns and a commensurate adjustment of the annuity rate.

During the same period annuity providers initiated a move towards higher yield fixed income assets, first through mortgage instruments and bonds of financial institutions, and after 2000 through corporate bonds. The increase in the holdings of corporate bonds was particularly impressive. The positive coefficient of SOFI may reflect the strategy of annuity providers to extract an increase in risk-adjusted returns by capturing the liquidity premium in corporate bonds, which are less traded and have a much lower liquidity than Central Bank and Government bonds. These institutional investors can afford to hold these less liquid assets given their longer time horizon and the nature of their liabilitiesannuities are long-term obligations, cannot be redeemed and the associated payouts are predictable. By capturing the liquidity premium and investing only in highly rated bonds (most corporate bonds are rated AA or higher), annuity providers may have felt that they were able to compete more aggressively in the annuities market while maintaining the degree of portfolio risk at acceptable levels. However, it is possible that the coefficients of SOFI and SOA also reflect a higher degree of portfolio risk and a higher risk premium demanded by annuitants.

The coefficients of SOFI and SOA are small, indicating that portfolio shifts have had only a moderate impact on the annuity rate. These results are consistent with several scenarios, including a small liquidity premium, and/or a partial and delayed sharing of higher returns with annuitants. In any case, it is noteworthy that higher portfolio returns tend to be partially shared with annuitants. 
The coefficient of LEV is positive and significant, reflecting the perception of higher risk involved in the combination of a riskier portfolio, large fixed liabilities, and a declining capital buffer. This result is consistent with the existence of a risk premium in the annuity rates of more leveraged companies, and has been obtained despite the fact that leverage ratios were measured at book values. The existence of an annuity guarantee would tend to weaken the impact of bankruptcy risk on the annuity rate, but the fact that the guarantee is partial may explain the result.

The coefficient of MIS was not significant, however. A larger duration mismatch implies more exposure of the provider to reinvestment risk, which should have a negative impact on the annuity rate. This result may be due simply to a deficient proxy for the duration mismatch. It may also be due to the negative correlation between the mismatch and the share of risk-free assets (or equivalently the positive correlation between MIS and SOFIsee the correlation matrix in Table 10). Some companies indicate that there were not sufficient corporate bonds with long duration, and in order to reduce the duration mismatch and avoid penalties under the capital rules they frequently needed to invest more in risk-free assets with long duration and sacrifice yield. ${ }^{14}$

The coefficient of MSHARE is negative and significant, suggesting that reputation, brand name, and the existence of a large distribution network have had a more powerful impact on the annuity rate than the pure scale effect during the sample period. It may also reflect the strategy of some small companies to gain market share by offering higher annuity rates, even at the expense of positive financial results. Equation (1) was re-estimated replacing MSHARE by the stock of technical reserves in order to explore further the existence of a scale effect, but the results did not change significantly (the correlation coefficient between two variables is 0.7 , as shown in the appendix).

The coefficient of the average premium, AP(EARLY), is positive and significant, indicating that the unit cost effect is more important than the longevity effect. This result is consistent with the regression results obtained by Thorburn, Rocha and Morales (2006) for money's worth ratios based on a separate dataset of individual annuities.

The coefficient of the commission rate, CR, has the expected negative sign and is significant. This result confirms the important role that brokers have played in the marketing of annuities in Chile, and will be further examined below. Finally, the coefficient of the Herfindahl index, HER(EARLY) is also negative and significant, confirming that a more concentrated annuities market tends to have a negative effect on the annuity rate. It is interesting to note that in the case of Chile the reverse happened during the sample period-HER(EARLY) declined as the annuities market became much more competitive during the 1990s, with the entry of several new companies.

As shown in Table 5, the regression also includes a dummy variable taking value 0 for the period 1993Q1-2001Q2, and value 1 for the rest of the sample, to control for a structural change in the annuities market during this period. The dummy was also multiplied by each of the right hand side variables in the model, to capture structural breaks in the individual coefficients. Based on t-statistics, the null hypothesis of no change in the slope was rejected for the variables RF, CR, and AP. Therefore, the final regression reported in

\footnotetext{
${ }^{14}$ Thorburn, Rocha, and Morales (2006) provide an econometric analysis of money's worth ratios based on a separate dataset of individual annuities (as opposed to the company level data used in this paper) and show that the money's worth ratios of individual annuities are negatively related to the duration of the annuity contract and the resulting exposure of the provider to reinvestment risk.
} 
Table 5 includes only the general dummy and the multiplicative dummies for only these three variables. ${ }^{15}$

The possibility of a structural break was first raised by Walker (2005), based on the observation that the scandal of large commissions and illegal rebates in the 1990s had prompted the Government to submit a new draft pension law to Congress in 2000. As mentioned in section 2, the draft law proposed, among other measures, an electronic quotation system and controls on broker's commissions. The draft law was only approved in 2004, but the threat of these legal changes may have changed dramatically the behavior of annuity brokers and providers. Walker (2005) tested the hypothesis of a structural break in the coefficient of the risk-free rate and of a unitary long-run coefficient at the end of the sample, and was not able to reject any of the two hypotheses. He concludes that the annuity rate became the key instrument of competition after 2000. These tests were performed through regressions of the annuity rate against lagged values of the risk-free rates and the annuity rate using monthly series of the two variables.

The results in Table 5 are largely consistent with Walker's and supportive of a structural break in the regression. It is interesting to note that two of the three coefficients that experienced a structural break are precisely those related to the risk-free rate and the commission rate. Taking into consideration the multiplicative dummy, the coefficient of the risk-free rate increases from 0.37 to 0.71 . The hypothesis of a unitary long-run coefficient at the end of the sample period was tested by means of a Wald statistic including the lagged dependent variable plus two lagged values for the risk free rate on the right hand side of the equation. The calculated value for the test was 0.65 , with a p-value of 0.42. Therefore, the null hypothesis of a unitary long-run coefficient at the end of the sample cannot be statistically rejected at conventional significance levels.

Equation (1) was re-estimated by the Fixed Effects model, but with the consistent asymptotic variance described above, with the results shown in Table 6 . All the variables remain significant, although the share of other risky assets, SOA, only remains significant at the 10 percent level. Considering that the coefficient for the MIS variable is statistically not different from 0, Equation (1) was re-estimated again by the Fixed Effects model with Robust Standard Errors, but excluding the MIS variable. As shown in Table 7, the exclusion of the MIS variable generally improves the t-statistics of all estimated coefficients, including the coefficient of SOA.

Tables 8 through 10 show the estimates of equation (1) with the annuity rate on normal old age policies as the dependent variable, replicating the same steps and procedures followed above. The coefficients have the expected signs and their values are similar to the ones obtained with the annuity rate on early retirement policies, although some of them become marginally non-significant at the 10 percent level, when estimated with robust standard errors. It is possible that these differences are simply due to a much smaller sample-as mentioned before, the number of new annuities classified as normal old age (i.e., bought by males and females above 65 and 60 years of age) is only 20 percent of total flow of new annuities, excluding disability and survivor annuities.

\footnotetext{
${ }^{15}$ The Fixed Effects model also includes dummies for each company but these are not reported.
} 


\section{Summary of Findings and Conclusions}

This paper formulated and estimated a reduced form equation for the annuity rate in Chile, based on a heuristic model of the demand and supply of annuities that incorporates company-level data. The estimated equation explains 80 percent of the variations of the annuity rate across companies and over time, and most of the coefficients have the expected sign, or signs that can be reasonably explained, and are significant.

The results of the exercise indicate the existence of a very competitive market for annuities in Chile. During the period under examination market competition took place through the annuity rate and broker activity. The illegal provision of cash rebates to annuitants (made possible by increasing commissions) became a powerful element of competition in the 1990s, and the results confirm the substitutability between annuity rates and commissions (which included the rebates) as two elements of price competition. The reduction in broker commissions and rebates in the 2000s translated into higher annuity rates and enhanced the role of the annuity rate as the main instrument of competition. The role of brokers has possibly been reduced but has not been eliminated.

During the past decade there were significant changes in the portfolio strategies of annuity providers. Most noticeably, there was a marked shift from government bonds towards higher yield fixed income assets, especially corporate bonds. It is possible that annuity providers have been able to generate an increase in risk-adjusted returns, as the corporate and mortgage bonds held in their portfolios have been issued primarily by highly rated companies (implying a low credit risk), and these instruments are usually held to maturity, allowing providers to extract the liquidity premium. Competitive pressures may have led providers to share the increased returns with annuitants, and the results confirm the small but positive impact of the share of higher yield assets on the annuity rate. However, it is possible that the coefficient reflects a risk premium as well.

Other portfolio variables such as financial leverage also have a positive impact on the annuity rate, possibly reflecting the presence of a risk premium. The presence of an annuity guarantee would tend to reduce the need for a risk premium, due either to higher portfolio risk or to higher leverage, but the result can still be explained, because the annuity guarantee is partial.

The coefficient of the Herfindahl index and the market share variable were both negative and significant, also reflecting the high degree of competition in the annuities market during the period under examination. The Herfindhal concentration index declined significantly during the 1990s with the entry of several new providers, and although it increased recently due to the exit of three firms, it remains substantially lower than at the beginning of the decade. Finally, the significance of the market share variable suggests that market reputation and a more extensive distribution network may allow larger companies to pay lower annuity rates and remain competitive. It may also reflect the attempts of smaller companies to gain market share through aggressive price strategies.

The results of the exercise are consistent with the results obtained by Thorburn, Rocha and Morales (2006), showing that money's worth ratios in Chile were high by international comparison. Both results indicate that the development of annuities markets must involve efforts to develop capital market instruments with long durations that can be purchased by annuity providers. The existence of a wide range of instruments with higher yields allows providers to hedge their risks while sharing a portion of the higher yields with annuitants 
when markets remain competitive. When annuities are indexed to prices these instruments need to be indexed as well. Developing indexed government bonds with long durations and facilitating the development of indexed private instruments will be one of the challenges faced by policy-makers in many reforming countries. ${ }^{16}$

${ }^{16}$ High income OECD countries are also making efforts to develop long duration indexed instruments to meet the needs of their institutional investors. See G-10 (2005) and Wolswijk and de Haan (2005). 
Table 5: Fixed Effects Estimation

Dependent Variable: AR(EARLY)

Sample: 1993Q1 - 2003Q3; Cross-Sections Included: 24

Total Panel Observations (Unbalanced): 693

$\mathbf{R}^{2}=0.7968 ;$ Adj. $\mathbf{R}^{2}=0.7854 ;$ F-Statistic $=69.4348 ;$ P-Value $($ F-Statistic $)=0.0000$

\begin{tabular}{c|cccc}
\hline Variable & Coefficient & Std. Error & t-Statistic & p-value \\
\hline C & 3.0257 & 0.1803 & 16.7840 & $0.0000^{* * *}$ \\
RF & 0.3652 & 0.0166 & 21.9809 & $0.0000^{* * *}$ \\
SOFI & 0.0029 & 0.0010 & 2.9696 & $0.0031^{* * *}$ \\
SOA & 0.0083 & 0.0031 & 2.6801 & $0.0075^{* * *}$ \\
LEV & 0.0115 & 0.0046 & 2.5309 & $0.0116^{* *}$ \\
MIS & -0.0208 & 0.0548 & -0.3800 & 0.7041 \\
MSHARE & -3.7609 & 0.7187 & -5.2331 & $0.0000^{* * *}$ \\
AP(EARLY) & 0.0002 & $2.46 * e^{-5}$ & 7.2057 & $0.0000^{* * *}$ \\
CR & -0.0437 & 0.0074 & -5.9007 & $0.0000^{* * *}$ \\
HER(EARLY) & -4.6728 & 0.9512 & -4.9128 & $0.0000^{* * *}$ \\
TREND & 0.0002 & 0.0019 & 0.0997 & 0.9206 \\
D & -1.2189 & 0.2011 & -6.0609 & $0.0000^{* * *}$ \\
RF*D & 0.4163 & 0.0382 & 10.8874 & $0.0000^{* * *}$ \\
AP(EARLY)*D & -0.0001 & $3.39 * e^{-5}$ & -4.0003 & $0.0001^{* * *}$ \\
CR*D & -0.0884 & 0.0264 & -3.3444 & $0.0009^{* * *}$ \\
\hline$* *$ significant at the $1 \%$ level;** significant at the $5 \%$ level;* significant at the $10 \%$ level $^{*}$ &
\end{tabular}

Table 6: Fixed Effects Estimation, with Robust Standard Errors

Dependent Variable: AR(EARLY)

Sample: 1993Q1 - 2003Q3; Cross-Sections Included: 24

Total Panel Observations (Unbalanced): 693

$\mathbf{R}^{2}=0.7968$; Adj. $\mathbf{R}^{2}=0.7854 ;$ F-Statistic $=69.4348 ;$ P-Value $($ F-Statistic $)=0.0000$

\begin{tabular}{c|cccc}
\hline Variable & Coefficient & Std. Error & t-Statistic & p-value \\
\hline C & 3.0257 & 0.2270 & 13.3270 & $0.0000^{* * *}$ \\
RF & 0.3652 & 0.0217 & 16.8099 & $0.0000^{* * *}$ \\
SOFI & 0.0029 & 0.0009 & 3.1631 & $0.0016^{* * *}$ \\
SOA & 0.0083 & 0.0046 & 1.7966 & $0.0729^{*}$ \\
LEV & 0.0115 & 0.0040 & 2.9086 & $0.0038^{* * *}$ \\
MIS & -0.0208 & 0.0489 & -0.4260 & 0.6703 \\
MSHARE & -3.7609 & 0.6535 & -5.7550 & $0.0000^{* * *}$ \\
AP(EARLY) & 0.0002 & $2.79 * e^{-5}$ & 6.3559 & $0.0000^{* * *}$ \\
CR & -0.0437 & 0.0180 & -2.4237 & $0.0156^{* *}$ \\
HER(EARLY) & -4.6728 & 0.7214 & -6.4778 & $0.0000^{* * *}$ \\
TREND & 0.0002 & 0.0021 & 0.0900 & 0.9283 \\
D & -1.2189 & 0.2703 & -4.5093 & $0.0000^{* * *}$ \\
RF*D & 0.4163 & 0.0491 & 8.4727 & $0.0000^{* * *}$ \\
AP(EARLY)*D & -0.0001 & $5.53 * e^{-5}$ & -2.4490 & $0.0146^{* *}$ \\
CR*D & -0.0884 & 0.0410 & -2.1565 & $0.0314^{* *}$ \\
\hline
\end{tabular}

$* * *=$ significant at the $1 \%$ level;** = significant at the $5 \%$ level;* = significant at the $10 \%$ level 
Table 7: Fixed Effects Estimation, with Robust Standard Errors

Dependent Variable: AR(EARLY)

Sample: 1993Q1 - 2003Q3; Cross-Sections Included: 24

Total Panel Observations (Unbalanced): 725

$R^{2}=0.7995 ;$ Adj. $R^{2}=0.7890 ;$ F-Statistic = 76.2162; P-Value $($ F-Statistic $)=0.0000$

\begin{tabular}{c|cccc}
\hline Variable & Coefficient & Std. Error & t-Statistic & p-value \\
\hline C & 3.0760 & 0.2187 & 14.0668 & $0.0000^{* * *}$ \\
RF & 0.3639 & 0.0209 & 17.4077 & $0.0000^{* * *}$ \\
SOFI & 0.0029 & 0.0009 & 3.1772 & $0.0016^{* * *}$ \\
SOA & 0.0086 & 0.0038 & 2.2509 & $0.0247^{* *}$ \\
LEV & 0.0110 & 0.0039 & 2.7967 & $0.0053^{* * *}$ \\
MSHARE & -3.4900 & 0.5727 & -6.0937 & $0.0000^{* * *}$ \\
AP(EARLY) & 0.0002 & $2.57 * e^{-5}$ & 6.8931 & $0.0000^{* * *}$ \\
CR & -0.0441 & 0.0180 & -2.4431 & $0.0148^{* *}$ \\
HER(EARLY) & -5.1390 & 0.7219 & -7.1191 & $0.0000^{* * *}$ \\
TREND & -0.0005 & 0.0020 & -0.2244 & 0.8225 \\
D & -1.2547 & 0.2437 & -5.1479 & $0.0000^{* * *}$ \\
RF*D & 0.4118 & 0.0457 & 9.0149 & $0.0000^{* * *}$ \\
AP(EARLY) D & -0.0001 & $3.95 * e^{-5}$ & -3.0191 & $0.0026^{* * *}$ \\
CR*D & -0.0808 & 0.0351 & -2.3035 & $0.0215^{* *}$ \\
\hline *** = significant at the $1 \%$ level;** significant at the $5 \%$ level;* significant at the $10 \%$ level
\end{tabular}

Table 8: Fixed Effects Estimation

Dependent Variable: AR(OLD)

Sample: 1993Q1 - 2003Q3; Cross-Sections Included: 24;

Total Panel Observations (Unbalanced): 675

$\mathrm{R}^{2}=0.7909 ;$ Adj. $\mathrm{R}^{2}=0.7787$; F-Statistic = 65.1110; $\mathrm{P}$-Value $(\mathrm{F}$-Statistic $)=0.0000$

\begin{tabular}{l|cccc}
\hline Variable & Coefficient & Std. Error & t-Statistic & p-value \\
\hline Constant & 2.7371 & 0.1741 & 15.7198 & $0.0000^{* * *}$ \\
RF & 0.3961 & 0.0182 & 21.8170 & $0.0000^{* * *}$ \\
SOFI & 0.0030 & 0.0011 & 2.7053 & $0.0070^{* * *}$ \\
SOA & 0.0070 & 0.0035 & 1.9727 & $0.0490^{* *}$ \\
LEV & 0.0121 & 0.0051 & 2.3558 & $0.0188^{* *}$ \\
MIS & 0.0247 & 0.0589 & 0.4187 & 0.6756 \\
MSHARE & -2.0611 & 0.8026 & -2.5680 & $0.0105^{* *}$ \\
AP(OLD) & 0.0001 & $1.87 * e^{-5}$ & 7.8900 & $0.0000^{* * *}$ \\
CR & -0.0280 & 0.0087 & -3.2029 & $0.0014^{* * *}$ \\
HER(OLD) & -3.4204 & 0.6212 & -5.5066 & $0.0000^{* * *}$ \\
TREND & 0.0055 & 0.0018 & 3.1318 & $0.0018^{* * *}$ \\
D & -1.8350 & 0.2148 & -8.5421 & $0.0000^{* * *}$ \\
RF*D & 0.5536 & 0.0406 & 13.6334 & $0.0000^{* * *}$ \\
AP(OLD)*D & -0.0001 & $3.80 * e^{-5}$ & -3.4935 & $0.0005^{* * *}$ \\
CR*D & -0.1340 & 0.0310 & -4.3171 & $0.0000^{* * *}$ \\
\hline *** = significant at the $1 \%$ level;** significant at the 5\% level;* significant at the $10 \%$ level
\end{tabular}


Table 9: Fixed Effects Estimation, with Robust Standard Errors

Dependent Variable: AR(OLD)

Sample: 1993Q1 - 2003Q3; Cross-Sections Included: 24

Total Panel Observations (Unbalanced): 675

$\mathbf{R}^{2}=0.7909 ;$ Adj. $\mathbf{R}^{2}=0.7787 ;$ F-Statistic $=65.1110 ;$ P-Value $($ F-Statistic $)=0.0000$

\begin{tabular}{l|cccc}
\hline Variable & Coefficient & Std. Error & t-Statistic & p-value \\
\hline Constant & 2.7371 & 0.1976 & 13.8525 & $0.0000^{* * *}$ \\
RF & 0.3961 & 0.0196 & 20.2453 & $0.0000^{* * *}$ \\
SOFI & 0.0030 & 0.0018 & 1.6559 & $0.0982^{*}$ \\
SOA & 0.0070 & 0.0039 & 1.7942 & $0.0733^{*}$ \\
LEV & 0.0121 & 0.0057 & 2.1144 & $0.0349^{* *}$ \\
MIS & 0.0247 & 0.0648 & 0.3810 & 0.7033 \\
MSHARE & -2.0611 & 0.9332 & -2.2088 & $0.0275^{* *}$ \\
AP(OLD) & 0.0001 & $1.67 * e^{-5}$ & 8.8551 & $0.0000^{* * *}$ \\
CR & -0.0280 & 0.0158 & -1.7696 & $0.0773^{*}$ \\
HER(OLD) & -3.4204 & 0.5765 & -5.9336 & $0.0000^{* * *}$ \\
TREND & 0.0055 & 0.0024 & 2.2893 & $0.0224^{* *}$ \\
D & -1.8350 & 0.2995 & -6.1268 & $0.0000^{* * *}$ \\
RF*D & 0.5536 & 0.0490 & 11.3063 & $0.0000^{* * *}$ \\
AP(OLD)*D & -0.0001 & $5.85 * e^{-5}$ & -2.2645 & $0.0239^{* *}$ \\
CR*D & -0.1340 & 0.0329 & -4.0739 & $0.0001^{* * *}$ \\
\hline$* * *=$ significant at the $1 \%$ level;** significant at the $5 \%$ level;* significant at the $10^{*}$ level $^{*}$
\end{tabular}

Table 10: Fixed Effects Estimation, with Robust Standard Errors

Dependent Variable: AR(OLD)

Sample: 1993Q1 - 2003Q3; Cross-Sections Included: 24

Total Panel Observations (Unbalanced): 675

$\mathbf{R}^{2}=0.7933 ;$ Adj. $\mathbf{R}^{2}=0.7821 ;$ F-Statistic $=71.3020 ;$ P-Value $($ F-Statistic $)=0.0000$

\begin{tabular}{l|cccc}
\hline Variable & Coefficient & Std. Error & t-Statistic & p-value \\
\hline Constant & 2.7150 & 0.1973 & 13.7634 & $0.0000^{* * *}$ \\
RF & 0.3987 & 0.0189 & 21.0905 & $0.0000^{* * *}$ \\
SOFI & 0.0031 & 0.0020 & 1.5814 & 0.1143 \\
SOA & 0.0075 & 0.0032 & 2.3210 & $0.0206^{* *}$ \\
LEV & 0.0122 & 0.0059 & 2.0549 & $0.0403^{* *}$ \\
MSHARE & -1.5149 & 0.9939 & -1.5242 & 0.1279 \\
AP(OLD) & 0.0001 & $1.63 * e^{-5}$ & 8.8935 & $0.0000^{* * *}$ \\
CR & -0.0273 & 0.0157 & -1.7313 & $0.0839^{*}$ \\
HER(OLD) & -3.5768 & 0.5652 & -6.3288 & $0.0000^{* * *}$ \\
TREND & 0.0050 & 0.0025 & 2.0480 & $0.0410^{* *}$ \\
D & -1.8897 & 0.2834 & -6.6676 & $0.0000^{* * *}$ \\
RF*D & 0.5483 & 0.0446 & 12.3071 & $0.0000^{* * *}$ \\
AP(OLD)*D & -0.0001 & $5.03 * e^{-5}$ & -2.1317 & $0.0334^{* *}$ \\
CR*D & -0.1257 & 0.0289 & -4.3552 & $0.0000^{* * *}$ \\
\hline *** = significant at the $1 \%$ level;** significant at the 5\% level;* significant at the $10 \%$ level
\end{tabular}


Annex Table 1: Pairwise Correlation Matrix

\begin{tabular}{|c|c|c|c|c|c|c|c|c|c|c|c|}
\hline & $\mathrm{RF}$ & SOA & SOFI & MSHARE & LEV & HER(EARLY) & AP(EARLY) & CR & MIS & ROFI(B) & ROFI(M) \\
\hline RF & 1.00 & & & & & & & & & & \\
\hline SOA & -0.39 & 1.00 & & & & & & & & & \\
\hline SOFI & -0.55 & 0.38 & 1.00 & & & & & & & & \\
\hline MSHARE & -0.06 & 0.17 & -0.18 & 1.00 & & & & & & & \\
\hline LEV & -0.05 & 0.06 & 0.05 & 0.03 & 1.00 & & & & & & \\
\hline HER(EARLY) & -0.58 & 0.06 & 0.20 & 0.07 & -0.07 & 1.00 & & & & & \\
\hline AP(EARLY) & -0.16 & 0.36 & 0.17 & 0.26 & 0.06 & 0.00 & 1.00 & & & & \\
\hline CR & 0.42 & -0.02 & -0.18 & -0.09 & 0.05 & -0.44 & -0.11 & 1.00 & & & \\
\hline MIS & -0.22 & 0.13 & 0.33 & -0.16 & -0.11 & 0.09 & 0.00 & -0.01 & 1.00 & & \\
\hline ROFI(B) 1/ & 0.86 & -0.23 & -0.37 & -0.07 & 0.05 & -0.59 & 0.00 & 0.43 & -0.15 & 1.00 & \\
\hline ROFI(M) 1/ & 0.92 & -0.30 & -0.44 & -0.08 & 0.04 & -0.68 & -0.04 & 0.47 & -0.19 & 0.97 & 1.00 \\
\hline RES & -0.43 & 0.52 & 0.30 & 0.71 & 0.09 & 0.18 & 0.42 & -0.16 & -0.01 & -0.26 & -0.32 \\
\hline
\end{tabular}




\section{References}

Ahn, S.C., and Low, S. (1996) "A Reformulation of the Hausman Test for Regression Models with Pooled Cross-Section Time-Series Data," Journal of Econometrics, 71, 30919.

Anderson, R. and S. Sundaresan (2000) "A Comparative Study of Structural Models of Corporate Bond Yields: An Exploratory Investigation.” Journal of Banking \& Finance 24, 255-269.

Andrews, D.W.K. (1991) "Heteroskedasticity and Autocorrelation Consistent Covariance Matrix Estimation,” Econometrica, 59, 817-58.

Arellano, M. (1987) “Computing Robust Standard Errors for Within-Group Estimators,” Oxford Bulletin of Economics and Statistics, 49, 431-34. . (2003) Panel Data Econometrics, Oxford University Press.

Baltagi, B.H. (2001) Econometric Analysis of Panel Data, Wiley \&Sons, Ltd.

Blume, M. E., D. B. Keim and S. A. Patel. "Returns and Volatility of Low-Grade Bonds 1977-1989.” The Journal of Finance, vol. 46, no.1, 49-74. March.

Brown, J., O. S. Mitchell, J. M. Poterba and M. J. Warshawsky, (2001) "The Role of Annuity Markets in Financing Retirement.” MIT Press, Cambridge, Massachusetts.

Choi, I. (2001) "Unit Root Tests for Panel Data," Journal of International Money and Finance, 20, 249-72.

Collin-Dufresne, P. and R. S. Goldstein (2001) "Do Credit Spreads Reflect Stationary Leverage Ratios?” The Journal of Finance, vol. LVI, no. 5, 1929-1957, October.

Cornell, B. and K. Green (1991) “The Investment Performance of Low-Grade Bond Funds.” The Journal of Finance, vol.46, no.1, 29-48, March.

Delianedis, G. and R. Geske (2001) “The Components of Corporate Credit Spreads: Default, Recovery, Tax, Jumps, Liquidity, and Market Factors.”

Duffee, G. R. (1998) “The Relation Between Treasury Yields and Corporate Bond Yield Spreads.” The Journal of Finance vol. LIII, no.6, December. (1999) "Estimating the Price of Default Risk." The Review of

Financial Studies vol.12, no.1, 197-226, Spring.

Elton, E. J., M. J. Gruber, D. Agrawal and C. Mann (2001) “Explaining the Rate Spread on Corporate Bonds.” The Journal of Finance vol. LVI, no.1, February. 
Ferreiro, A. et al (2002) El Sistema Chileno de Pensiones Derivado de la Capitalizacion Individual, Superintendencia de Administradoras de Fondos de Pensiones, Santiago, Chile.

Fisher, R.A. (1932) Statistical Methods for Research Workers, Oliver \& Boyd, $4^{\text {th }}$ Ed.

G-10 (2005), “Ageing and pension system reform: implications for financial markets and economic policies”. Unpublished manuscript, September.

Green, W. (1997) Econometric Analysis, Prentice Hall, New Jersey.

Honda, Y. (1985) "Testing the Error Components Model with Non-Normal Disturbances," Review of Economic Studies, 52, 681-90.

Huang, Jing-Zhi and Ming Huang (2003) "How Much of the Corporate-Treasury Yield Spread is Due to Credit Risk?”

Im, K.S., Pesaran, M.H., and Shin, Y. (2003) “Testing for Unit Roots in Heterogeneous Panels,” Journal of Econometrics, 115, 53-74.

James, E., G. Martinez and A. Iglesias, (2004) "The Payout Stage in Chile: Who Annuitizes and Why?” Unpublished Manuscript.

Levin, A., Lin, C.F., and Chu, C. (2002) "Unit Root Tests in Panel Data: Asymptotic and Finite-Sample Properties,” Journal of Econometrics, 108, 1-24.

Liu, S., H. Qi and C. Wu (2004) “Taxes, Default Risk and Corporate Bond Yield Spreads: A Structural Approach,” June.

Maddala, G.S., and Wu, S. (1999) "A Comparative Study of Unit Roots with Panel Data and a New Simple Test,” Oxford Bulletin of Economics and Statistics, 61, 631-52.

, and Kim, I.M. (1999) Units Roots, Cointegration, and Structural Change, Cambridge University Press.

Ng, S., and Perron, P. (2001) "Lag Length Selection and the Construction of Unit Root Tests with Good Size and Power,” Econometrica 69, 1519-54.

Perron, P. (1989) "The Great Crash, the Oil Price Shock and the Unit Root Hypothesis," Econometrica, 57, 1361-1402.

Rocha, R., and C. Thorburn (2006), Developing Annuities Markets: The Experience of Chile. The World Bank. Washington DC.

Sarig, O. and A. Warga (1989) "Bond Price Data and Bond Market Liquidity.” Journal of Financial and Quantitative Analysis, vol. 24, no. 3, 367-378, September.

Thorburn, C., R. Rocha and M. Morales (2006) “An Analysis of Money’s Worth Ratios in Chile”, Unpublished Manuscript. The World Bank. Washington DC. 
Walker, E. (2005), “Annuity Markets: Competition, Regulation and Myopia? December. Unpublished manuscript. Catholic University of Chile.

Wolswijk, G. and J. de Haan (2005) "Government Debt Management in the Euro Area: Recent Theoretical Developments and Changes in Practice”. European Central Bank Occasional Paper No. 25, March.

Wooldridge, J.F. (2002) Econometric Analysis of Cross Section and Panel Data, MIT Press, Cambridge, Massachusetts. 